\title{
DINÁMICA USURPATORIA DE APROVECHAMIENTOS COMUNALES EN CASTILLA FEUDAL (SIGLOS XIII-XIV)
}

\section{USURPATIVE DYNAMICS OF COMMUNAL USE IN CASTILLA (THIRTEENTH AND FOURTEENTH CENTURIES)}

\author{
Lucio B. MIR \\ Universidad Nacional de La Pampa
}

\section{Resumen}

El desarrollo de la propiedad privada durante el feudalismo se inscribe en una red de problemas interpretativos abordados desde múltiples enfoques disciplinarios y tradiciones teóricas. Este trabajo indaga factores de cambio y de continuidad ligados a la individualización de derechos de propiedad y su correlato en fenómenos estructurales que afectaron a las comunidades aldeanas. Explora la dinámica usurpatoria en diversos territorios de Castilla, los usos preferentes de espacios agro-ganaderos por las elites campesinas y sus implicancias en el afianzamiento de diferenciaciones internas que reconfiguran la base consuetudinaria de esas comunidades. Identifica el perfil de las jerarquías de derechos de uso en las prácticas colectivas del campesinado y sus efectos institucionales en función de formas individualizadoras de aprovechamientos pastoriles. Interpela procesos contradictorios en el desempeño del poder monárquico respecto a la validez efectiva de las regulaciones socio-jurídicas que regían los patrones organizativos del mundo rural, revisando los efectos polarizadores de los accesos privilegiados a montes y herbajes comunales.

Palabras clave: campesinado-ganadería-cercamientos-propiedad privada-estado feudal.

\begin{abstract}
Private property development during feudalism happens within a network of interpretative problems addressed from multiple disciplinary approaches and theoretical traditions. This work enquires into certain factors of change and continuity related to property rights individualization and their complement in structural phenomena that affected village communities. It explores the usurpative dynamics in diverse territories of Castilla, the preferential uses of agro-cattle spaces by peasant elites and their implications for establishing inner differentiations that reshape the customary basis of those communities. It identifies the profile of rights-of-use hierarchies in peasantry's collective practices and its
\end{abstract}


institutional effects in terms of individualizing ways of peasant uses. It questions contradictory processes in monarchic power achievement regarding the effective validity of socio-legal regulations which ruled organizational patterns in the rural world, examining the polarizing effects of privileged accesses to forests and communal herbages.

Key words: peasantry, livestock, fencing, private property, feudal state.

\section{INTRODUCCIÓN}

La investigación acerca de los procesos de cambio en las comunidades rurales de la Edad Media conlleva abordajes que reflejan la influencia de múltiples perspectivas. Las interpretaciones sobre el cambio socioeconómico general y del campesinado en particular durante la crisis del feudalismo recorren diversos trabajos de Abel (2005), Postan (1981), Brenner (1988), Hilton (1988), Dyer (1991), Allen (2004) y Hall (2014), que constituyen parte de las referencias directrices de la literatura especializada en torno a la Inglaterra medieval y moderna, aun cuando sus implicancias trascienden el marco historiográfico inglés.

Hilton ha discernido la lógica política y económica de las elites campesinas examinando costumbres aldeanas y condiciones preferentes para el disfrute individual de derechos comunes (1988: 60-61) ${ }^{1}$; incidía ello en el encumbramiento de sectores del campesinado que, en áreas del sudeste insular, producían para el mercado y elevaron su nivel de vida y riqueza privada (Postan, 1981: 145); (Dyer, 1991: $226 \mathrm{y}$ 238); Britnell (1993: 121).Estos fenómenos se reformulan a la luz de fuentes documentales de reciente publicación y de distintas conceptualizaciones, observándose patrones de cambio y de continuidad en los sistemas agrarios de Inglaterra que se visualizan en larga duración y que comportan lecturas interdisciplinarias sobre aristas que exceden el ámbito de la economía feudal (Dimmock, 2015).

La apertura hacia nuevos abordajes respecto al tratamiento de las aldeas castellanas luce enriquecedora, con sensibles repercusiones de la historiografía española del mundo rural en los centros académicos de Europa (Feller, 2015: 11). Aspectos determinantes de las instituciones aldeanas y de los derechos consuetudinarios integran el eje analítico de la obra de Genicot, que sitúa a Castilla y León en una dinámica de reducción de tierras comunales (Genicot, 1993:102), problema enfocado desde diversos ángulos y perspectivas teóricas (Martín Viso, 2000), (Gerbet, 2003), (Clemente Ramos, 2004), (García Oliva, 2013).

\footnotetext{
${ }^{1}$ Sobre la resistencia campesina al despojo de bosques comunales, ver Una historia simbólica de la Edad Media occidental de Michel Pastoureau
} 
La configuración de las elites campesinas de Castilla es objeto de revisión crítica en cuanto a sus núcleos interpretativos y bases empíricas (Astarita, 2005), mientras que las modalidades de resistencia contra actos usurpatorios de la propiedad comunal y de usos ganaderos presentan renovadas formulaciones en el planteamiento de Monsalvo Antón (2005-2006). Los factores constitutivos de la institucionalidad del orden monárquico presiden distintos trabajos de Ladero Quesada (2014: 137139), quien analiza aspectos centrales de los poderes políticos y disecciona el funcionamiento del Estado feudal.

Una relectura de las condiciones políticas y socio-jurídicas que afectaron el acceso campesino a los aprovechamientos comunales es esbozada en este artículo en función de los cambios y permanencias que reflejan diversas fuentes, en especial los enunciados normativos.

\section{COMPETENCIA POR LOS PASTOS COMUNALES}

Hacia fines del siglo XIII las elites campesinas del norte de Castilla rehusaban el acceso a espacios comunales a aquellos pastores que carecían de "cartas de vecindad" atinentes a su distrito; resistían normativas (ordenanzas de Sancho IV) homologatorias de la libertad de pastos en el territorio del reino (Peña Pérez, 1994: 429 y 433), que definieron incumbencias de la fiscalidad real (derechos de pastos) para usos de los herbajes, derechos que conformaban ingresos ordinarios (Casado Alonso, 2010: 38). En el comportamiento de esas elites gravitaron "principios de estratificación" (Oliva Herrer, 2007:309), traducidos en asimetrías del patrimonio vecinal e inscriptos en estructuras sociales que dan cuenta de la peculiaridad de los agrosistemas.

El desarrollo de estos agrosistemas revela fenómenos locales y regionales del ordenamiento demográfico, político y espacial, identificables con precedentes de sólido anclaje respecto a la morfología económica y socio-jurídica del feudalismo ${ }^{2}$. Los procesos de transformación de los patrones organizativos e institucionales de la economía agraria, en particular de la base productiva del campesinado, se exploran aquí desde las prácticas silvo-pastoriles, usurpación y cercado de tierras y su correlato en la trashumancia ovina.

\footnotetext{
${ }^{2}$ Ver precedentes en la obra de Max Weber, quien en su The Agrarian Sociology of Ancient Civilizationspostula diversas formas de feudalismo. Ver también el trabajo de PEÑA BOCOS, E.: La atribución social del espacio en la Castilla altomedieval. Una nueva aproximación al feudalismo peninsular, Santander, 1995, Universidad de Cantabria, pp.288-290 y el libro de FELLER, L. Campesinos y señores en la Edad Media (Siglos VIII-XV), Valencia, 2015, Universitat de Valencia, pp. 229-259.
} 
En tales procesos operaban modalidades de resistencia que los campesinos desplegaron frente a los señores para impedir la actualización de las rentas antiguas en el contexto de relaciones feudales (Clemente Ramos, 2004: 181). Relaciones que subsumían variantes entre tierras adscriptas a censos fijos establecidos por la costumbre y el uso de tierras con contratos de arriendo a precios de mercado. Ello se acredita en privilegios y cartas de arrendamiento que involucraban a monasterios, concejos y órdenes militares (Gutiérrez Pajares, 1993: 108-110), evidenciándose pleitos entre señores y de estos frente a las potestades concejiles, con pastos y bosques como factor de disputa del proceso de estructuración productiva (Ruiz Gómez, 1990: 21); (Pastor, 1991-1992: 51) y en cuya evolución interactuaron formas específicas de dominio individualizado, hasta cierto punto contrapuestas a las configurativas de la dependencia servil (Miranda García, 2008:131-134).

La presión señorial sobre las comunidades de aldea tendía a desarticular su estabilidad patrimonial (Ruiz Gómez, 1990: 213), inhibiéndose asimismo el acceso a montes y pasturas de aprovechamiento comunitario por injerencia directa de los caballeros villanos (Genicot, 1993: 142). Este y otros factores reforzaron diferenciaciones económicas entre campesinos, acreditadas con el avance de derechos individuales a la propiedad (Martínez Sopena, 1985: 215-217) y en los contrastes interfamiliares que distinguen cargas solariegas que recaían sobre una fuerza de trabajo con medios de subsistencia sometidos a control señorial, es decir, a magnates que adehesaron espacios comunales (Martínez García, 2001: 326).

La sustentabilidad campesina en la organización y explotación consuetudinaria de espacios pastoriles se resentía por restricciones a los usos abiertos ganaderos -de alta incidencia en sus estrategias y formas productivas-, no sólo disminuidos por despojos señoriales: la dinámica usurpatoria atañía a los concejos, que solían realizar adehesamientos de "propios" para disfrute de las elites concejiles (García Oliva,2013: 105). El manejo individualizado de dehesas del común (áreas cercadas para cría ovina y otros ganados) se antepuso a ciertos derechos de vecindad, un resorte lesivo que originaba querellas por la privatización de la propiedad colectiva (Sánchez Benito, 1994: 170).

A raíz de tales usurpaciones se formalizó un contencioso entre la villa de Atienza y la aldea de Cogolludo. A inicios del siglo XIV el concejo de Atienza rehusaba el aprovechamiento comunitario de sotos y alijares cuando incautó semovientes que los vecinos de Cogolludo llevaron a apacentar a los términos de la villa; pero el derecho de pastos de los aldeanos de Cogolludo se encuadraba en competencias conferidas por la monarquía a la orden de Calatrava, cuyos maestres instituyeron 
jurisdicción sobre esa aldea y dirigían enfrentamientos y concordias mediatizadas por la intervención regia (Layna Serrano, 1945: 122 y 507).

El adehesamiento de heredades y campos comunales respondía, en cierta medida, al propósito de neutralizar el ingreso de hatos trashumantes; esto favorecía la propiedad privada con el resguardo particular de herbajes para las actividades ganaderas. Sugiere un fortalecimiento de la individualización del patrimonio, que parece transmitir un privilegio del rey Alfonso X cuando dispuso que determinadas heredades de los caballeros villanos de Valladolid (1265) y de Palencia (1270) se transformen en "prados adehesados" (Reglero de la Fuente, 1994: 224), lo que permitiría consolidar el manejo individual de tierras y rebaños con el control efectivo de superficies cercadas (Reglero de la Fuente, 1994: 225 y 228).

Los procesos legales proporcionan referencias respecto de las querellas que involucraron a las comunidades de Peñafiel y Cuéllar y el señorío de Valbuena para restablecer el uso consuetudinario de un "lugar de realengo" (Muñoz Gómez, 2010: 74), que la abadía impedía limitando la libertad de pastos; la resistencia a esta restricción reconoce una voluntad activa del concejo de Peñafiel, pues el adehesamiento abacial de campos abiertos tuvo como réplica el expolio de rebaños que, arrebatados de las tierras cercadas, exacerbó la relación litigiosa:

El abad de Valbuena se me querello muchas veces del Concejo de Peñafiel [...]en cortarles sus deffesas [dehesas] e robarles sus ganados et quebrantarles sus grangias [granjerías] (Rey Alfonso X, [1274] 2011: 166-168).

La resistencia campesina a los cercados se detecta en este y otros testimonios; la legislación regia (Partidas) instituyó regulaciones de usos ganaderos y manejo de aguas, un conjunto de preceptos y mandatos establecidos por el Estado feudal (Astarita, 2005: 85-112) ${ }^{3}$. El derecho de las comunidades a resistir legalmente actos expropiatorios dimanó de sus fueros y del ejercicio superior de la jurisdicción que el monarca efectivizaba mediante cargas fiscales (herbazgos) y otras prerrogativas, lo que agudizó competencias conflictivas perceptibles en tensiones políticas que atravesaron el sistema feudal (Peña Bocos, 1995: 59) ${ }^{4}$. En ocasiones estas competencias pusieron de relieve la dificultad para coordinar la organización del acceso colectivo a aquellos recursos que no eran de propiedad individual.

\footnotetext{
${ }^{3}$ Ver también "Political Society and the Late Medieval State" de Jean-Philippe Genety Política, seguridad y orden público en la Castilla de los Reyes Católicos de Jorge Urosa Sánchez.

${ }^{4}$ Cargas contributivas institucionalizadas en los impuestos de montazgo y herbazgo para el tránsito de los rebaños trashumantes por montes y pastos comunales.
} 
Una controversia por el uso de herbajes entre el monasterio de Valbuena y el concejo de Vellosillo devino en querella que la justicia regia administró para dirimir pleito por "pastos comunes", pronunciándose la sentencia y escritura de concordia a favor de los intereses concejiles (representados por doña María Suárez) con la prohibición expresa de labrar las tierras de Castil de Cisla, lo que revalidaba el antiguo derecho del concejo para su aprovechamiento como dehesa colectiva (Herrero Salas, 2011: 149 y 159).

\section{CERCADOS Y TRASHUMANCIA OVINA}

La vulneración de derechos vecinales asoma en fuentes normativas; el debilitamiento de las "buenas costumbres" supuso alterar las potestades para usos abiertos de recursos pastoriles, sujetos a la tradición consuetudinaria de "comunidad de pastos" (Linage Conde, 1973: 178); las dehesas de propiedad común sufrieron usurpaciones en la comarca de Zamora por vía de una cesión coactiva a los señores, quienes detentaron el control de bienes críticos para la economía aldeana (Martín Viso, 2000: 319). Las apropiaciones señoriales socavaron los medios de subsistencia campesina (Rodríguez Picavea,1994: 214), impactando en el complemento de labriegos y pequeños criadores; pero este avance señorial no siempre interfería en los circuitos de trashumancia, debido al acuerdo de "reparto de los derechos de paso" en el contexto de una expansión agraria que se extiende hasta mediados del siglo XIII (Martín Viso, 2000: 341).

La aristocracia magnaticia fue artífice de una especialización ganadera que, bajo el influjo de distintos factores (entre ellos el comercio exterior de lana en el siglo XIV), repercutía en las acumulaciones privadas de tierras y propiciaría cierta tendencia a la "monopolización" de los rebaños (Martín Viso, 2000: 270 y 332); este proceso reconoce puntos de anclaje en el mercado inmobiliario y en la concentración de dehesas por señores laicos y eclesiásticos, acentuándose con el cercado de herbazales las potencialidades de la ganadería extensiva en la meseta meridional (Gerbet, 2003:155-156).

Los antecedentes respecto a la regulación de la trashumancia pastoril se plasman en normativas forales que el poder monárquico fijaba desde el siglo XI (Sevilla Guzmán, 1979: 52-53). El control municipal de esta ganadería se infiere a partir de un privilegio relativo al desplazamiento estacional de los ovinos, según lo acredita

\footnotetext{
${ }^{5}$ Marie-Claude Gerbet, La ganadería medieval en la península ibérica, Barcelona, Crítica, 2003, pp. 155156.
} 
el fuero de Cuenca (1189): tipifica la exención de caloñas (pena pecuniaria) para los dueños de animales en tránsito que apacentaban en la serranía de Cuenca, uno de los ejes nodales de la futura Mesta (Pastor de Togneri, 1968: 218).

La necesidad de que "...los ganados pasen por la cannada [Ledesma] salvos e seguros quando van a los estremos e vienen", sugiere un esquema organizativo con que los alcaldes de Mesta supervisaron las actividades trashumantes (Martín Expósito y Monsalvo Antón, 1986: 69-71), tuteladas por el soberano con el auxilio de ordenanzas que pautaban su reglamentación, fenómeno éste que exhibe ángulos de contacto con las regulaciones sobre pasturas en la Inglaterra de fines del siglo XIII (Hall, 2014: 128-132) y con prácticas ganaderas de la cabaña campesina (Clemente Ramos, 2004: 63).

El comportamiento de las elites campesinas (jerarquías del mundo aldeano) no fue ajeno a acciones de adehesado de campos abiertos para explotación individualizada (García Oliva, 2013: 105), lo que matiza la línea interpretativa que identifica a esta minoría con la defensa de los ancestrales derechos de propiedad comunitaria y al poder señorial como factor excluyente en el avance de usurpaciones (Luchía, 2003). Los caballeros villanos asumieron funciones institucionales que les permitían el ejercicio de una coerción para el aprovechamiento particular de los terrenos comunes, materializada en la reorganización y distribución de montes y pasturas a favor de sus intereses (Pastor, 1991-1992: 59).

El poder de la caballería villana para usufructuar una explotación individualizada de pastos y otros recursos comunales lograría redefinir ciertas condiciones primigenias del orden consuetudinario, que devino tensionado, en parte, por la conflictiva privatización de esas tierras (Ruiz, 2004: 77). Sin embargo, la propiedad privada se desarrollaría en base a sus cualidades sociales constitutivas pues, aunque este derecho tutelaba la apropiación individual de los productos del trabajo, también regía para diversos recursos extraídos de las tierras comunales (Astarita, 1993: 74-75).

La funcionalidad de los concejos articulaba jerárquicamente un poder político e institucional que la monarquía arbitra a través de mediaciones corporativas, y en cuya confirmación (1227) a Uceda, Buitrago, Hita y Guadalajara el rey declara el patrimonio comunal de los herbajes (González, 1976: 192 y 337). Refrendaba los derechos de vecindad reconocidos a los usos de montes y pastos (Jimeno, 1958: 494), aunque los actos de individualización impuestos por los caballeros implicaron un privilegio para las elites campesinas: la validez de ciertas costumbres vecinales persistía de jure, pero condicionada de facto por jerarquías estamentales que permitieron acentuar diferenciaciones acumulativas. 
Un texto normativo aporta evidencia respecto de la propiedad concejil en tierras dependientes de Segovia; la carta puebla de la aldea de El Espinar (1297) estipula la titularidad "comunal" de su dehesa, aun cuando parece habilitar un uso privativo permanente (jerarquía de derechos de uso) para explotación diferenciada por parte de los caballeros, sin que su alcance comporte un acto usurpatorio:

Et otrosi damos para defesa [dehesa] e para salido para los ganados para esta puebla sobredicha del espinar que ayan que sea comunal para todos. Et en esta defesa que pascan y los bueys e las uacas que fueren de arar de los caualleros en todo tiempo (Puyol y Alonso, 1904: 12-13).

La prescripción traduce aquí una matriz estamental, convergente con las formas organizativas de una economía agro-pastoril que regulaba el acceso al espacio socio-productivo mediante jerarquías de derechos de uso, pese a que la personalidad comunitaria permanecía para el aprovechamiento de variados recursos (bellota, leña, pesca), recursos tanto más críticos cuanto más endeble lucía la existencia del alodio campesino (Pastor, 1991-1992: 51).

El accionar de la monarquía en relación con el poblamiento fronterizo se ejecutaba conforme criterios político-jurídicos que tipifican características de las concesiones de tierras; la base legal de algunos privilegios otorgados para constituir "heredamientos" determinó la expresa prohibición de enajenar el patrimonio inmueble (condicionalidad de la propiedad) ${ }^{6}$, una prohibición que perdía validez normativa transcurrido el lapso de diez años, lo que se constata en el caso de Requena. Los caballeros que hubieren de poblar este alfoz gozarían de los atributos legales de la propiedad, aunque sujetos a pautas restrictivas para su enajenación mercantil y extramercantil:

Con montes con fuentes con ríos con pastos con entradas et con salidas et con todos sus términos et con todas sus pertenencias [...] pero en tal manera que lo non hayan poder de lo vender, ni de lo empeñar, ni de lo enagenar del dia que este nuestro privilegio fuere fecho fasta diez años; et de los diez años adelante, que fagandello todo lo que quisieren (de Hinojosa, 1919: 166-167).

La protección de las comunidades supuso un aspecto clave de la política de la monarquía al sustentar el entramado socio-organizativo de una extensa red de poblamiento que, a través de los concejos vecinales y otras vías de instrumentalización, posibilitó la colonización agraria y controles territoriales relativamente afianzados (Jular Pérez-Alfaro, 2010: 424-427); un complejo proceso en el que las elites

\footnotetext{
${ }^{6}$ En referencia al carácter no absoluto del derecho de propiedad en el sistema feudal, ver Economía, Derecho, Historia. Conceptos y realidades de Pierre Vilar.
} 
campesinas operaban como resortes del poder institucional en la interacción de intereses estamentales que presidían las relaciones del monarca con la formación social.

\section{CRISIS ESTRUCTURAL Y MALOS USOS}

El contexto de una pronunciada crisis agraria (Izquierdo Benito, 2006: 371; Engels,1992: 220-221 y García Sanz,1981:87-95) subtiende las premisas de esta interpretación. Difiere con la idea de que las Partidas reflejan las condiciones generales de un mundo rural inmerso en "estabilidad creciente" (Sánchez Domingo, 2009:273). La crisis sistémica contribuyó a reformular las bases jurídicas del ordenamiento público y afectó aspectos sensibles de la correlación política que vinculaba el centro monárquico con la aristocracia feudal (Nieto Soria, 2006: 203).

El avance de los malos usos (Fernández Conde, 2004: 87) resultaría mitigado por concesiones señoriales ("fueros buenos") que aligeraban cargas y tributos exigidos a los productores directos ${ }^{7}$. A inicios del siglo XIII las prestaciones de campesinos dependientes (sernas) permanecían activas, una modalidad primigenia de renta señorial; lo atestigua un documento de 1218 , en donde el abad del monasterio de Oña alude a los servicios en trabajo que enuncia un texto prescriptivo:

Concedimus quod non eatis de cetero ad sernam, id est ad laborem seruilem faciendum, nec uso nec successores vestri, sicut ceteri collaciinos triuadunt (Del Álamo, 1950: 517).

A fines del siglo XIII el peso de estas prestaciones había decaído, aun cuando los ingresos señoriales se reconvertían en el marco de una transformación usurpatoria que se valía de la absorción de propiedades abaciales y comunales (Ruiz Gómez, 1990:110), en parte explotadas bajo arriendo por campesinos enriquecidos. La usurpación masiva de comunales tendía a reconfigurar la base socio-patrimonial de las elites campesinas y de señores, alterando los patrones de poblamiento aldeano. La crisis potenció la competencia interseñorial, con fuertes disputas por grandes espacios silvopastoriles integrados al cenobio de Oña, reconocibles en áreas comarcanas de Santa Olalla de Villilla y en San Pedro de Cot (García González, 1972: 18).

Esta crisis agraria agudizaba las tensiones del proceso de individualización de la propiedad, redefiniendo las formas de acceso a aprovechamientos comunitarios y

\footnotetext{
${ }^{7}$ El imperativo jurídico se interpreta aquí en línea con las formulaciones de Hilton, para quien los preceptos legales serían parte de la estructura económica de la sociedad, claves para institucionalizar la extracción regular de excedentes. Ver la "Introducción" de El debate Brenner. Estructura de clases agraria y desarrollo económico en la Europa preindustrial (T.H. Aston y C.H.E Philpin, eds) de Rodney Hilton.
} 
que los agentes diferenciadores permiten visibilizar; ello erosionaba los medios de subsistencia de los aldeanos, generándose una "contradicción entre los mecanismos reproductivos de la unidad doméstica campesina y las relaciones de propiedad privada sobre la tierra" (Astarita, 2005: 154). De ahí que la industria rural a domicilio constituya un emergente disruptivo que tradujo la enajenación de sectores campesinado de las condiciones sociales de posesión de su propio trabajo, cambio inscripto en una creciente polarización (Da Graca, 2009: 116) ${ }^{8}$ y el desarrollo de formas de "propiedad privada" (Martín Viso, 2000:312 y Feller, 2015:124).

Pero el proceso usurpatorio de los espacios comunales provocó resistencias y solía neutralizarse cuando la práctica de restitución imprimía validez efectiva a los derechos aldeanos. Este juego oscilante expresaba las tensiones que conllevaron vínculos coactivos coexistentes con fenómenos económicos (las fuerzas del mercado), que tendían a reconfigurar las formas de propiedad (individualización), y en cuyo despliegue el componente salarial pudo fungir de complemento para las familias campesinas empobrecidas (Clemente Ramos, 2004: 86 y 102).

La crisis económica desestabilizó las condiciones sociales que posibilitaban a la clase señorial reproducir su dominación política: los fueros buenos oficiaron de instrumentos para contrarrestar las migraciones campesinas, que impusieron serios desajustes a los sistemas productivos (Mínguez, 1994: 307 y García Sanz y otros, 1981: 89). El fenómeno migratorio se acredita durante la segunda mitad del siglo XIII, y un historiador escruta en la Tierra de Campos el despoblamiento, en 1270, de 14 aldeas (Vaca Lorenzo, 1995: 40). Este fenómeno recrudece durante el siglo XIV, pues con datos del registro arqueológico se han conseguido cuantificar 800 despoblados en comarcas de Castilla y León (Quirós Castillo y Bengoetxea Rementería, 2010: 361). Un autor asevera que ello no estaría evidenciando una "crisis de fondo" de la economía agraria (Ladero Quesada, 2014: 160), aun cuando las significativas concesiones a las comunidades parecen dar cuenta de la debilidad estructural que experimentaba su desempeño.

Ante el reacomodamiento de las fuerzas productivas, la legislación regia había prescrito autonomía a las familias solariegas para abandonar sus aldeas sin el consentimiento del señor (Muñoz y Romero, 1847: 133); ello supuso resignar rentas detraídas a los campesinos por medio de las exacciones inherentes al dominio útil, dado que la movilidad y el abandono deterioraban la capacidad tributaria aldeana (Astarita, 2005: 119).

\footnotetext{
${ }^{8}$ Sobre el impacto de la polarización en la economía feudal, ver The Origin of Capitalism in England, 14001600 de Spencer Dimmock.
} 
En las Partidas quedó formalizado el hecho prescriptivo que reconoce la movilidad campesina:

Y este tal [habitante de aldea] puede salir cuando quisiere de la heredad con las cosas muebles que hubiere, mas no puede enajenar aquel solar ni demandar la mejoría que alli hubiera hecho (Gibert, 1985: 325).

Movilidad campesina que resentía los ingresos señoriales, minimizándose el alcance de las coacciones con que extraían el excedente económico, afectado por una productividad declinante (crisis de subsistencia) agravada a raíz de la despoblación rural. De ahí que los nobles sublevados contra Alfonso X (1272) exigieron que se prohibiese a los campesinos de sus dominios emigrar a las nuevas pueblas (Ladero Quesada, 2014: 125). El fenómeno incidía fuertemente en la evolución de la renta feudal, que ha sido cifrada con datos obtenidos de un dominio leonés: el monasterio de Sahagún computa, entre 1338 y 1353, una contracción total del 53,67\% (Campagne, 2005: 97).

Este fenómeno desnuda la índole misma de una lógica contradictoria: con sus tipificaciones específicas, los derechos de numerosas comunidades aparecen revalidados en normativas que regularon su movilidad y recrean privilegios colectivos a partir de pautas y principios consuetudinarios. En ocasión de su investidura como señor de Ledesma (1311), don Sancho (nieto de Alfonso X) confirma la vigencia de antiguos fueros para esta villa y le confiere franquezas fiscales (Martín Expósito y Monsalvo Antón, 1986: 42).

A fines del siglo XIV el poblado de Piedrahíta explotaba aprovechamientos comunes apoyándose en privilegios que la monarquía le había dispensado (Luis López, 1987: 14). A los campesinos dependientes del señorío de Villena se les reconocían derechos a los pastos comunales, lo que sugiere que el proceso de feudalización en la comarca de Albacete reprodujo las relaciones de dominación sin alterar prácticas agrarias colectivas, es decir, en lo que atañe al disfrute comunitario de tierras concejiles (Pretel Marin y Rodríguez Llopis, 1998: 225).

Las potestades del rey se reafirman mediante distintos actos jurídicos. Un conflicto entre el obispado de Cuenca y el cuerpo concejil trasunta el intento del cabildo catedralicio de apropiarse de una parte de los montes comunales, lo que hizo necesaria la intervención regia para dirimir el contencioso; el rey ratifica (24 de septiembre de 1290) la plena legalidad de las atribuciones vecinales en cuanto al aprovechamiento de pasturas y de leña (Díaz Ibáñez, 1994: 138), que habían sido vedadas por el poder episcopal para acaparar su disfrute. La dinámica usurpatoria se sostuvo en 
el siglo XIV, dado que diferentes señoríos convirtieron a los aprovechamientos comunales en recursos de explotación privada (Sánchez Benito, 1997: 93).

Hacia 1319 recrudece un conflicto entre el monasterio de Sandoval y el concejo de Villaturiel por el control de los pastos de Sotillo, que el cenobio había declarado propios rehusando el acceso a los aldeanos de Villaturiel, inhibidos del uso comunitario ante el avance de la privatización del espacio (Herrero Jiménez, 2003: 199). El asalto a las tierras comunales se documenta en múltiples prácticas usurpatorias (Marcos Martín, 1997: 62-63). Una dinámica conflictiva que guardaría correlación indirecta con el gran comercio de exportación de lana a los centros manufactureros de Flandes.

Los principios consuetudinarios de las comunidades campesinas resistieron intensas ofensivas, que las Cortes de Madrid (1329) dejan traslucir; el rey Alfonso XI intercedía debido a las irrupciones que sus agentes cometieron en el medio rural con la apropiación de ejidos, montes, dehesas y heredamientos pertenecientes a los concejos (Gibert, 1985: 319-320), lo que instauró una secuencia de demandas legales de sostenida trayectoria, en parte motivada porque la monarquía había dispuesto la nulidad de mercedes, cartas y privilegios que beneficiaron a la aristocracia.

\section{CONCLUSIÓN}

Con la usurpación de tierras comunales y el fortalecimiento de la propiedad privada afloran aristas de un proceso conflictivo que denota la pluralidad de fenómenos en los que discurría el cambio estructural; este cambio conlleva variantes de desarrollo inscriptas en incipientes formas de transición, cuya dinámica luce en parte supeditada a la reconfiguración de los sistemas agrarios de la economía feudal.

En Castilla, esta dinámica se vio interferida y limitada (con alcances que debieran profundizarse) con instrumentos judiciales que permitieron restituir espacios apropiados, revalidándose derechos de las comunidades respecto de su patrimonio colectivo (Monsalvo Antón, 2005-2006: 37-74). Ello no impidió que el proceso de cambio socio-económico cristalizara rupturas en los medios de subsistencia del campesinado, objetivadas, en parte, en la importancia de un proletariado rural (Clemente Ramos, 2004:94). La traducción política e institucional de este proceso emana bajo principios que regían las prescripciones sobre la propiedad privada, que resurgía a través del derecho romano y dio fundamento a los "dueños particulares" de tierras cercadas: 
Los dueños particulares de estanques, lagunas o charcas que se hallen en tierras cercadas están autorizados, en virtud del derecho de propiedad, para pescar (Partidas, 1844:758).

Gravitando sobre la tensión entre rupturas y continuidades, las fuerzas actuantes operaron inmersas en una lógica jurídico-política que expresó el juego contradictorio entre los derechos aldeanos y el afianzamiento de unas elites campesinas investidas de funciones institucionales (caballería villana), que ejercían cargos concejiles y detentaban el control de un patrimonio individualizado sirviéndose de jerarquías de uso, de la guerra, y de la actividad agroganadera; esta dinámica fortalecía una diferenciación acumulativa que provino, en alguna medida, del "acceso privilegiado a las zonas de pasto comunes" (Morsel, 2008: 283-284).

La apropiación y explotación individualizada de tierras comunitarias socavaron las bases sociales del campesinado al transformar sus relaciones reproductivas y de posesión del patrimonio vecinal, en cuyo seno institucionalizaba el acceso a medios de subsistencia, y que la crisis sitúa en aguda contradicción con las exacciones rentísticas del poder señorial. Exacciones en parte reconducidas a través de las potestades del centro monárquico en un antagónico juego de fuerzas. Estos fenómenos resintieron la estabilidad del mundo aldeano, fenómenos que la monarquía lograría rebalancear, hasta cierto punto, con sentencias judiciales restitutorias de la propiedadcomunal.

\section{BIBLIOGRAFÍA}

\section{FUENTES PRIMARIAS}

ALFONSO X EL SABIO. (1844): Las Siete Partidas del Rey Alfonso, tomo II, Barcelona. DE HINOJOSA, E. (1919): Documentos para la historia de las instituciones de León y de Castilla (siglos X-XIII), Madrid, Junta para la Ampliación de Estudios e Investigaciones Científicas.

DEL ÁlAMO, J. (1950): Colección diplomática de San Salvador de Oña, 822-1284, tomo II, Madrid, CSIC.

HERRERO JIMÉNEZ, M. (2003): Colección documental del monasterio de Villaverde de Sandoval (1132-1500), León, Centro de Estudios e Investigación San Isidoro.

HERRERO SALAS, F. (2011): Colección diplomática del monasterio cisterciense de Valbuena de Duero (siglos XI-XV), Valencia.

LUIS LÓPEZ, C. (1987): Colección documental del Archivo Municipal de Piedrahita (13721549), Ávila, Diputación Provincial.

MARTÍN EXPÓSITO, A. y MONSALVO ANTÓN, J. M (eds.). (1986): Documentación 
medieval del Archivo Municipal de Ledesma, Salamanca, Diputación Provincial.

MUÑOZ y ROMERO, T. (1847): Colección de fueros municipales y cartas pueblas de los reinos de Castilla, León, corona de Aragón y Navarra, tomo I, Madrid, Imprenta de José M. Alonso.

PUYOL y ALONSO, J. (1904): "Una puebla en el siglo XIII (cartas de población de El Espinar)", RevueHispanique, tomo XI, N³7-40, (Separata).

RODRÍGUEZ MARTÍNEZ, F. (2010): Corpus documental de Coca, Madrid, Visión Libros.

\section{FUENTES SECUNDARIAS}

ABEL, W. (2005): Agricultural Fluctuations in Europe. Fromthe Thirteenthto the Twentieth Centuries, Londres, Taylor \& Francis.

ALLEN, R.C. (2004): Revolución en los campos. La reinterpretación de la revolución agrícola inglesa, Zaragoza, Universidad de Salamanca.

ALVARADO PLANAS, J. (2009): El municipio medieval: nuevas perspectivas, Madrid, Sanz y Torres.

ÁLVAREZ BORGE, I. (2001): Comunidades locales y poderes feudales en la Edad Media, La Rioja, Universidad de La Rioja.

ASTARITA, C. (1992): Desarrollo desigual en los orígenes del capitalismo, Buenos Aires, Tesis 11. (1993): "Estructura social del concejo primitivo de la Extremadura castellanoleonesa. Problemas y controversias". Anales de historia antigua y medieval, Facultad de Filosofía y Letras (UBA), vol. 26, 1993, pp.47-118. (2005): Del feudalismo al capitalismo. Cambio social y politico en Castilla y EuropaOccidental, 1250-1520, Valencia, Universitat de Valencia.

ASTON, T.H y PHILPIN, C.H.E (eds.). (1988): El debate Brenner. Estructura de clases agraria y desarrollo económico en la Europa preindustrial, Barcelona, Crítica.

BOIS, G. (2003): La gran depresión medieval: siglos XIV-XV. El precedente de una crisis sistémica, Valencia, Universitat de Valencia.

BRITNELL, R. (1993): The commercialization of English Society, 1000-1500, Cambridge, Cambridge UniversityPress.

CAMPAGNE, F.A. (2005): Feudalismo tardio y revolución, Buenos Aires, Prometeo. CASADO ALONSO, H. (2010): "La economía en las Españas medievales (c.1000-c.1450)", en Francisco Comín y otros (eds.), Historia Económica de España, siglos X-XX, Barce- lona, Planeta. pp. 13-50.

CLEMENTE RAMOS, J. (2004): La economía campesina en la Corona de Castilla (10001300), Barcelona, Crítica.

DA GRACA, L. (2009): Poder politico y dinámica feudal. Procesos de diferenciación social en distintas formas señoriales (siglos XIV-XVI), Valladolid, Universidad de Valladolid. 
DÍAZ IBÁÑEZ, J. (1994): "Monarquía y conflictos Iglesia-concejos en la Castilla bajomedieval. El caso del obispado de Cuenca (1280-1406)", La España medieval, № 17, Madrid, Editorial Complutense. pp. 133-156.

DIMMOCK, S. (2015): The Origin of Capitalism in England, 1400-1600, Chicago, Haymarket Books.

DYER, C. (1991): Niveles de vida en la baja Edad Media. Cambios sociales en Inglaterra,

c. 1200-1520, Barcelona, Crítica.

ENGELS, O. (1992): "La crisis en Castilla durante el siglo XIV”, enSeibt, F. y Eberhard, W. (eds.), Europa 1400. La crisis de la baja Edad Media, Barcelona, Crítica, pp. 213-224.

FELLER, L. (2015): Campesinos y señores en la Edad Media. Siglos VIII-XV, Valencia, Universitat de Valencia.

FELLER, L. y WICKHAM, C. (2005): Le Marché de la terreauMoyen Age, Rome, ÉcoleFrancaise de Rome.

FERNÁNDEZ CONDE, F. (2004): La España de los siglos XIII al XV. Transformaciones del feudalismo tardio, San Sebastián, Nerea.

GARCÍA GONZÁLEZ, J. J. (1972): Vida económica de los monasterios benedictinos en el siglo XIV, Valladolid, Universidad de Valladolid.

GARCÍA OLIVA, M.D. (2013): “Ganadería, poblamiento y dehesas en los concejos de realengo de Extremadura (siglos XIII-XV)”, en P. de la Cruz Díaz Martínez, F. L. Corral e I. Martín Viso (eds.), El historiador y la sociedad, Salamanca, Ediciones Universidad de Salamanca. pp. 101-114.

GARCÍA SANZ. A. (1981): Propiedades del cabildo segoviano. Sistemas de cultivo y modos de explotación de la tierra a fines del siglo XIII, Salamanca, Universidad de Salamanca. GENET, J.P. (2009): "Political Society and the Late Medieval State", en Troels Dahlerup and Per Ingesman (eds.), New Approaches to the History of Late Medieval and Early

Modern Europe, Copenhagen, FlemmingLundgreen, pp. 11-36.

GENICOT, L. (1993): Comunidades rurales en el Occidente medieval, Barcelona, Crítica. GERBET, M. C. (2003): La ganadería medieval en la península ibérica, Barcelona, Crítica. GIBERT, R. (1985): “La comunidad campesina en León y Castilla durante la Edad Media”,

Estudios en Homenaje a don Claudio Sánchez Albornoz en sus 90 años, Buenos Aires, Facultad de Filosofía y Letras, Instituto de Historia de España, pp. 315-337.

GONZÁlEZ, J. (1976): Repoblación de Castilla la Nueva, vol. II, Madrid, Universidad Complutense.

GOODY, J. (1990): La lógica de la escritura y la organización de la sociedad, Madrid, Alianza.

GUTIÉRREZ PAJARES, M. T. (1993): El monasterio cisterciense de San Andrés de Arroyo, Palencia, Diputación Provincial. 
HALL, D. (2014): The Open Fields of England, Oxford, Oxford UniversityPress. HILTON, R.: (1988): Conflicto de clases y crisis del feudalismo, Barcelona, Crítica.

IZQUIERDO BENITO, R. (2006): "La crisis del siglo XIV en Castilla y sus repercusiones demográficas: los despoblados y su análisis arqueológico”, en AA.VV., Homenaje al Dr. Rafael Sancho de San Román, Toledo, Real Academia de Bellas Artes y Ciencias Históricas de Toledo, pp.365-382.

JIMENO, E. (1958): “La población de Soria y su término en 1270”, Estudios Geográficos, $\mathrm{N}^{\circ} 73$, Madrid, CSIC, pp. 487-512.

JULAR PÉREZ-ALFARO, C. (2010): “Monarquía y gobierno territorial en la Baja Edad Media: oficiales mayores y menores del rey", en AA.VV., Monasterios, espacio y sociedad en la España cristiana medieval, Logroño, Instituto de Estudios Riojanos, pp. 395427.

LADERO QUESADA, M. A. (2014): Poder político y sociedad en Castilla. Siglos XIII al $X V$, Madrid, Dykinson.

LAYNA SERRANO, F. (1945): Historia de la Villa de Atienza, Madrid, CSIC.

LINAGE CONDE, A. (1973): Los orígenes del monacato benedictino en la Península Ibérica, vol. III, León, CSIC.

LUCHÍA, C. (2003): "Propiedad comunal y lucha de clases en la baja Edad Media castellanoleonesa. Una aproximación a la dialéctica de la propiedad comunal", Anales de Historia Antigua, Medieval y Moderna, 36, Buenos Aires, UBA, pp. 235-268.

MARCOS MARTÍN, A. (1997): "Evolución de la propiedad pública municipal en Castilla la Vieja durante la época moderna”, Studia Historica. Historia Moderna, 16, Universidad de Salamanca. pp. 57-100.

MARTÍN VISO, I. (2000): Poblamiento y estructuras sociales en el norte de la Península Ibérica (siglos VI-XIII), Salamanca, Ediciones Universidad de Salamanca.

MARTÍNEZ GARCÍA, L. (2001): "El solar castellano en la Edad Media central. De la participación de señores y campesinos en la pequeña producción familiar”, en Ignacio Álvarez Borge [coord.], Comunidades locales y poderes feudales en la Edad Media, La Rioja, Universidad de la Rioja, pp.289-330.

MARTÍNEZ SOPENA, P. (1985): La Tierra de Campos Occidental. Poblamiento, poder y comunidad del siglo $X$ al $X V$, Valladolid, Diputación Provincial.

MÍNGUEZ J. M. (1994): "Las sociedades feudales, 1. Antecedentes, formación y expansión (siglos VI al XIII)", Historia de España II, Madrid, Nerea.

MIRANDA GARCÍA, F. (2008): "Sociedad y economía hispano-cristianas (siglos VIIIXII)”, en Fermín Miranda García y Yolanda Guerrero Navarrete (eds.) Medieval. Territorios, sociedades y culturas, Madrid, Sílex Ediciones, pp. 125-162. 
MONSALVO ANTÓN, J. M. (2005-2006): "Percepciones de los pecheros medievales sobre usurpaciones de términos rurales y aprovechamientos comunitarios en los concejos salmantinosy abulenses", Edad Media. Revista de Historia, Nº7, pp.37-74.

MORSEL, J. (2008): La aristocracia medieval. El dominio social en Occidente (siglos V$X V)$, Valencia, Universitat de Valencia.

MUÑOZ GÓMEZ, V. (2010): "El concejo de Peñafiel. Gobierno y sociedad en una villa vallisoletana", Miscelánea Medieval Murciana, XXXIV, pp. 71-81.

NIETO SORIA, J. M (dir.). (2006): La monarquía como conflicto en la Corona castellanoleonesa (c. 1230-1504), Madrid, Sílex Ediciones.

OLIVA HERRER, H. (2007): "El mundo rural en la Corona de Castilla en la baja Edad Media: dinámicas socioeconómicas y nuevas perspectivas de análisis”, Edad Media. Revista de Historia, Universidad de Valladolid, $N^{\circ} 8$, pp.295-328.

PASTOR, R. (1991-1992): "El feudalismo en Castilla", Anuario, 15, Escuela de Historia, Universidad Nacional de Rosario, pp. 49-61.

PASTOR DE TOGNERI, R. (1968): "Poblamiento, frontera y estructura agraria en Castilla la Nueva (1085-1230)", Cuadernos de Historia de España, XLVII-XLVIII, pp.171-255. PASTOUREAU, M. (2006): Una historia simbólica de la Edad Media occidental, Buenos Aires, Katz Editores.

PEÑA BOCOS, E. (1995): La atribución social del espacio en la Castilla altomedieval. Una nueva aproximación al feudalismo peninsular, Santander, Universidad de Cantabria.

PEÑA PÉREZ, F. J. (1994): "La economía burgalesa en la plena Edad Media", en AA.VV. Burgos en la plena Edad Media, Burgos, Asociación Provincial de Libreros de Burgos, pp. 411-458.

POSTAN, M. (1981): Ensayos sobre agricultura y problemas generales de la economía medieval, Madrid, Siglo XXI.

PRETEL MARIN, A. y RODRÍGUEZ LLOPIS, M. (1998): El Señorío de Villena en el siglo XIV, Albacete, Instituto de Estudios Albacetenses.

QUIRÓS CASTILLO, J. A. y BENGOETXEA REMENTERÍA, B. (2010): Arqueología III. Arqueología medieval y posmedieval, Madrid, Universidad Nacional de Educación a Distancia.

REGLERO DE LA FUENTE, C. M. (1994): Espacio y poder en la Castilla medieval: los montes de Torozos (siglos X-XIV), Valladolid, Diputación Provincial.

RODRÍGUEZ PICAVEA, E. (1994): La formación del feudalismo en la meseta meridional castellana. Los señoríos de la orden de Calatrava en los siglos XII y XIII, Madrid, Siglo XXI Editores.

RUIZ, T.F. (2004): From Heaven to Earth. The Reordering of Castilian Society, 1150-1350, Princeton, Princeton UniversityPress. 
RUIZ GÓMEZ, F. (1990): Las aldeas castellanas en la Edad Media. Oña en los siglos XIV $y X V$, Madrid, CSIC.

SÁNCHEZ BENITO, J. M. (1994): Las tierras de Cuenca y Huete en el siglo XIV. Historia económica, Cuenca, Universidad de Castilla-La Mancha.

SÁNCHEZ BENITO, J. M. (1997): “Concejo y sociedad en Cuenca (siglos XIII-XIV)”, en García Marchante, Joaquín S. y López Villaverde, Ángel L. (coord.), Relaciones de poder en Castilla: el ejemplo de Cuenca, Cuenca, Ediciones Universidad de Castilla La Mancha, pp. 83-102.

SÁNCHEZ DOMINGO, R. (2009): "La autonomía concejil frente a las encomiendas monásticas", en AlvaradoPlanas, J. (ed.), El municipio medieval: nuevas perspectivas, Madrid, Sanz y Torres. pp.269-293.

SEIBT, F, y EBERHARD, W. (1992): Europa 1400. La crisis de la baja Edad Media, Barcelona, Crítica.

SEVILLA GUZMÁN, E. (1979): La evolución del campesinado en España, Barcelona, Península.

UROSA SÁNCHEZ. J. (1998): Política, seguridad y orden público en la Castilla de los Reyes Católicos, Madrid, INAP.

VACA LORENZO, A. (1995): "Recesión económica y crisis social de Castilla en el siglo XIV”, en Chris Wickham, Henry Kamen y Elena Hernández Sandoica (eds.), Las crisis en la historia, Salamanca, Ediciones Universidad de Salamanca.

VILAR, P. (1983): Economía, Derecho, Historia. Conceptos y realidades, Barcelona, Ariel. WEBER, M. (1976): The Agrarian Sociology of Ancient Civilizations, Londres, New LeftBooks.

Lucio B. MIR

luciomir3@hotmail.com 